\title{
MEMBANGUN KOMITMEN PELANGAN MELALUI KUALITAS PELAYANAN DAN TRUST PELANGGAN TOKO SWALAYAN
}

\author{
Salamatun Asakdiyah \\ Staf Pengajar Fakultas Ekonomi dan Bisnis \\ Universitas Ahmad Dahlan \\ e-mail : salamatun_2009@yahoo.com
}

\begin{abstract}
This research aimed to test influence between service quality, customer trust also interaction between service quality and customer trust in the building of customer commitment of supermarket. This research efforted in Pamella Supermarket in Yogyakarta. Sample categorized with sampling convenience method and purposive sampling. Data collection efforted by giving list of quetion to the respondent that is contains about service quality, customer trust and customer commitmnet. This research use moderator Regression Analysis. In the other side, $T$ test and $F$ test are used to the asked hypothesis.This result of partially regression coefficient test with $T$ test shows that service quality, customer trust also interaction betwen them influence significantly to customer commitment. In the other side coefficient regression with $F$ test's result shows that variables of service quality, customer trust also interaction between them 60 th influence to customer commitment. Variable of service quality, customer trust also interaction between them are able to explain customer commitment variable up $81,9 \%$ and the rest is $18,1 \%$ caused by anather variables that is not included in the research model.
\end{abstract}

\begin{abstract}
ABSTRAK
Penelitian ini bertujuan untuk menguji pengaruh kualitas pelayanan, trust pelanggan serta interaksi antara kualitas pelayanan dan trust pelanggan dalam pembentukan komitmen pelanggan. Penelitian dilakukan pada Pamella Swalayan Kota Yogyakarta. Sampel ditentukan dengan metode convenience sampling dan purposive sampling. Pengumpulan data dilakukan dengan cara memberikan daftar pertanyaan kepada responden yang berisi tentang kualitas pelayanan, trust pelanggan serta komitmen pelanggan. Alat analisis yang digunakan adalah Analisis Regresi Moderator. Sedangkan untuk menguji hipotesis yang dikemukakan digunakan uji t dan uji F. Uji t digunakan untuk menguji koefisien regresi secara parsial dan uji F digunakan untuk menguji koefisien regresi secara serempak (bersama-sama). Sedangkan untuk mengetahui seberapa besar variabel-variabel kualitas pelayanan, trust pelanggan serta interaksi antara kualitas pelayanan dan trust pelanggan mampu menjelaskan variabel komitmen pelanggan digunakan analisis koefisien determinasi.Hasil pengujian koefisien regresi secara parsial dengan uji t menunjukkan bahwa kualitas pelayanan, trust pelangan serta interaksi antara kualitas pelayanan dengan trust pelanggan secara signifikan mempengaruhi komitmen pelanggan. Sedangkan hasil pengujian koefisien regresi secara bersama-sama menunjukkan bahwa variabel kualitas pelayanan, trust pelanggan serta interaksi antara kualitas pelayanan dengan trust pelanggan secara bersama-sama berpengaruh terhadap komitmen pelanggan. Variabel-variabel kualitas pelayanan, trust pelanggan serta interaksi antara kualitas pelayanan dengan trust pelanggan mampu menjelaskan variabel
\end{abstract}


komitmen pelanggan sebesar $81,9 \%$ dan sisanya sebesar 18,1\% disebabkan oleh variabel lain yang tidak dimasukkan dalam model penelitian.

Kata Kunci : Kualitas Pelayanan, Trust Pelanggan, dan Komitmen Pelanggan

\section{PENDAHULUAN}

Globalisasi dan liberalisasi perdagangan dunia mengakibatkan perubahan yang cepat pada lingkungan bisnis. Penyesuaian diri dengan perubahan yang ada menjadi kebutuhan utama perusahaan agar bisa bersaing di pasar global. Persaingan dapat dimenangkan apabila perusahaan mempunyai keunggulan kompetitif. Keunggulan kompetitif dapat dicapai melalui jalinan hubungan jangka panjang antara perusahaan dengan pelanggan dengan cara membangun komitmen pelanggan. Hal ini menunjukkan bahwa komitmen pelanggan memainkan peran penting dan dapat dijadikan sebagai dasar untuk pengembangan keunggulan kompetitif berkelanjutan yaitu keunggulan yang dapat direalisasi melalui upayaupaya pemasaran.

Komitmen pelanggan dapat dibangun melalui peningkatan kualitas pelayanan dan pencapaian trust pelanggan. Kualitas pelayanan merupakan salah satu faktor utama pemilihan barang dan jasa bagi pelanggan. Sedangkan tujuan perusahaan menghasilkan barang dan jasa untuk dapat memuaskan dan meningkatkan trust pelanggan. Hal ini berarti trust pelanggan akan tercapai apabila kualitas pelayanan yang diberikan perusahaan dapat memenuhi kebutuhan pelanggan. Tercapainya trust pelanggan akan meningkatkan komitmen pelanggan. Dengan demikian, jalinan hubungan jangka panjang antara perusahaan dengan pelanggan akan terbangun melalui anteseden-anteseden komitmen pelanggan.

Salah satu bidang usaha yang merasakan dampak perkembangan ekonomi global adalah bisnis ritel. Bisnis ritel meliputi semua kegiatan yang melibatkan penjualan barang atau jasa secara langsung kepada konsumen akhir untuk penggunaan pribadi dan bukan bisnis (Kotler, 1997). Hal ini berarti bisnis ritel merupakan bagian dari saluran distribusi yang berperan sebagai penghubung antara kepentingan produsen dengan konsumen.

Dalam persaingan yang semakin ketat ini, bisnis ritel menghadapi tantangan utama yaitu mengelola komitmen pelanggan sehingga akan menciptakan loyalitas pelanggan. Usaha untuk memperoleh pelanggan yang loyal bukanlah pekerjaan yang mudah, sehingga memerlukan perhatian yang lebih serius terutama para pemasar. Dengan demikian, pelanggan yang loyal merupakan aset penting bagi perusahaan, bahkan loyalitas pelanggan mempunyai hubungan yang positif dengan profitabilitas (Rowley dan Dawes, 1999).

Mengingat arti pentingnya komitmen pelanggan dalam pencapaian tujuan perusahaan, maka tulisan ini berupaya untuk menganalisis pengaruh anteseden-anteseden komitmen pelanggan yang mencakup kualitas pelayanan dan trust pelanggan ritel dalam melakukan pembelian ulang terhadap penciptaan loyalitas pelanggan, sehingga terjalin hubungan jangka panjang antara perusahaan dengan pelanggan.

\section{TINJAUAN PUSTAKA}

\section{Service Quality (Kualitas Pelayanan)}

Service Quality merupakan suatu cara untuk membandingkan antara persepsi layanan yang diterima pelanggan dengan layanan yang sesungguhnya diharapkan pelanggan (Fitzsimmons \& Fitzsimmons, 1994; Parasuraman, Zeithaml dan Berry, 1988). Apabila layanan yang diharapkan pelanggan lebih besar dari layanan yang nyata-nyata diterima pelanggan maka dapat dikatakan bahwa layanan tidak bermutu. Sedangkan jika layanan yang 
diharapkan pelanggan lebih rendah dari layanan yang nyata-nyata diterima pelanggan maka dapat dikatakan bahwa layanan bermutu, dan apabila layanan yang diterima sama dengan yang diharapkan maka layanan tersebut dikatakan memuaskan (Fitzsimmons \& Fitzsimmons, 1994). Dengan demikian Service Quality merupakan suatu cara untuk mengetahui seberapa jauh perbedaan antara kenyataan dan harapan pelanggan atas layanan yang diterima (Parasuraman, Zeithaml dan Berry, 1988).

Analisis SERVQUAL secara empirik telah diuji pada jasa bank, jasa telepon dan sebagainya. Akan tetapi analisis SERVQUAL tidak selalu berhasil diterapkan pada bisnis ritel. Pada kenyataannya hanya sedikit penelitian yang dilakukan dalam bisnis ritel. Dalam penelitian yang dilakukan oleh Dabholkar, Thorpe dan Rentz (1996) diajukan beberapa dimensi kualitas jasa ritel. Ketiga peneliti ini mengkombinasikan review dan literatur ritel dan SERVQUAL, sehingga berhasil diajukan 5 dimensi kualitas jasa ritel.

Kelima dimensi kualitas jasa ritel ini meliputi : (1) Physical Aspects, merupakan dimensi yang mencakup tentang daya tarik dari aspek fisik dan kemudahan pelanggan dalam menemukan barang yang dibutuhkan, (2) Reliability, merupakan dimensi yang mencakup tentang ketepatan pemenuhan janji kepada pelanggan, (3) Personal Interaction, merupakan dimensi yang mencakup interaksi personal antara pelanggan dengan karyawan, (4) Problem Solving, merupakan dimensi yang berkaitan dengan pemberian solusi terhadap masalah yang dihadapi pelanggan ketika sedang berbelanja atau solusi terhadap keluhan yang disampaikan oleh pelanggan atas layanan yang diterima, seperti pengembalian dan penukaran barang yang telah dibeli pelanggan, dan (5) Policy, merupakan dimensi yang berhubungan dengan kebijakan toko guna merespon tuntutan atau kebutuhan pelanggan, seperti penyediaan barang yang berkualitas, penerimaan pembayaran dengan kartu kredit serta penyediaan tempat parkir yang memadai.

Para ahli memandang bahwa Trust menjadi faktor penting yang dapat menentukan keberhasilan relationship marketing (Berry, 1995; Morgan dan Hunt, 1994; Garbarino dan Johnson, 1999). Trust muncul dari kerjasama yang berulang-ulang antara beberapa partner (Gulati, 1995) atau hubungan yang meningkat antara pelanggan dengan perusahaan. Pemahaman tentang konsep Trust dimulai oleh Parasuraman, Zeithaml dan Berry (1985) yang memandang bahwa pelanggan harus memiliki kepercayaan terhadap perusahaan, pelanggan akan merasa aman dalam melakukan transaksi dengan perusahaan dan transaksi yang dilakukan akan dijamin secara pasti.

Beberapa ahli mendefinisikan Trust sebagai perilaku dari kepercayaan terhadap reliabilitas dan integritas perusahaan untuk memenuhi harapan pelanggan pada masa yang akan datang (Moorman et.al, 1992; Morgan dan Hunt, 1994; Selnes, 1998. Worchel (1979) dalam Lau dan Lee (1999) mendefinisikan Trust sebagai kesediaan (willingness) seseorang untuk menggantungkan dirinya pada pihak lain dengan resiko tertentu. Demikian juga Moorman, Deshpande dan Zaltman (1992) memahami Trust sebagai kesediaan seseorang untuk menggantungkan dirinya pada pihak lain yang terlibat dalam pertukaran karena ia mempunyai keyakinan pada pihak lain tersebut, dan Trust akan ada apabila satu pihak mempunyai keyakinan terhadap pihak lain yang terlibat dalam pertukaran yang mempunyai reliabilitas dan integritas (Morgan dan Hunt, 1994).

Berdasarkan beberapa definisi tersebut diatas menunjukkan arti pentingnya kepercayaan, reliabilitas dan integritas dalam konsep Trust, sehingga perusahaan dapat memenuhi kebutuhan pelanggan. Dengan demikian Trust memegang peran penting dalam jalinan hubungan jangka panjang antara pelanggan dengan perusahaan terutama yang mencakup kepercayaan pelanggan mengenai kualitas, reliabilitas, integritas dari jasa yang disampaikan perusahaan. 
Kualitas pelayanan dan Trust pelanggan merupakan dua faktor yang memegang peran penting dalam menjalin hubungan jangka panjang antara perusahaan dengan pelanggan. Pemahaman tentang konsep Trust dimulai oleh Parasuraman, Zeithaml dan Berry (1985) yang memandang bahwa pelanggan harus memiliki kepercayaan terhadap perusahaan, pelanggan akan merasa aman dalam melakukan transaksi dengan perusahaan dan transaksi yang dilakukan akan dijamin secara pasti. Trust mempunyai peran penting dalam jalinan hubungan jangka panjang antara pelanggan dan perusahaan terutama yang mencakup kepercayaan pelanggan mengenai kualitas, reliabilitas, integritas dan jasa yang disampaikan perusahaan (Morgan dan Hunt, 1994).

Selain Trust, maka komitmen juga menjadi factor penting yang mempengaruhi keberhasilan relationship marketing (Dwyer, Schurr dan Oh's, 1987; Morgan dan Hunt, 1994; Garbarino dan Johnson, 1999). Dwyer, Schurr dan Oh's (1987) mengadapatasi marital relationship model yang menggambarkan pentingnya pengembangan sumber hubungan pertukaran. Ide sentral dalam teori partnership mengimplikasikan pada perbedaan antara Trust dan komitmen. Konsep ini membedakan bentuk partner antara pelanggan dengan perusahaan dalam orientasi terhadap transaksi yang berulang (Berry, 1995).

Komitmen dapat didefinisikan sebagai keinginan abadi untuk memelihara nilai keberlangsunan hubungan (Moorman, et al, 1992; Garbarino dan Johnson, 1999). Selain itu, komitmen didefinisikan sebagai perjanjiaan yang eksplisit maupun implicit dari hubungan yang continue antara partner yang saling bertukaran. Komitmen ini mengimplikasikan adanya kemauan untuk penghargaan jangka pendek untuk menghasilkan keuntungan yang lebih lama (Dwyer, et al, 1987). Demikian juga Selnes (1995) mendefinisikan komitmen sebagai tindakan atau komunikasi yang mengarah kepada adaptasi terhadap kebutuhan pelanggan secara spesifik.

Hubungan antara kualitas pelayanan dengan komitmen pelanggan didasarkan pada konsep loyalitas pelanggan yang dapat dibangun melalui 4 tahap, yaitu loyalitas kognitif, loyalitas afektif, loyalitas konatif dan loyalitas tindakan. Dalam tahapan tersebut kualitas pelayanan dimasukkan sebagai loyalitas kognitif, Trust Pelanggan dimasukkan sebagai loyalitas afektif, sedangkan komitmen pelanggan dimasukkan sebagai loyalitas konatif (Dharrmmesta, 1999).

Komitmen pelanggan diyakini sebagai variable sentral dalam relationship marketing (Morgan dan Hunt, 1994). Sedangkan Berry dan Parasuraman (1991) berpendapat bahwa relationship marketing dalam bisnis jasa dapat dibangun melalui pondasi mutual commitment, sedangkan mutual commitment dipengaruhi oleh kualitas pelayanan yang diterima pelanggan. Selain itu, komitmen pelanggan dapat dibangun melalui kualitas pelayanan superior yang diterima pelanggan dari perusahaan apabila dibandingkan dengan kualitas pelayanan perusahaan lainnya (Dick dan Basu, 1994).

Kualitas pelayanan dan trust pelanggan merupakan dua faktor yang memegang peran penting dalam menjalin hubungan jangka panjang antara organisasi dengan pelanggan. Pemahaman tentang konsep trust dimulai oleh Parasuraman, Zeithaml dan Berry (1985) yang memandang bahwa pelanggan harus memiliki kepercayaan terhadap organisasi, pelanggan akan merasa aman dalam melakukan transaksi dengan organisasi dan transaksi yang dilakukan akan dijamin secara pasti. Trust mempunyai peran penting dalam jalinan hubungan jangka panjang antara pelanggan dan organisasi terutama yang mencakup kepercayaan pelanggan mengenai kualitas, reliabilitas, integritas dan jasa yang disampaikan organisasi (Morgan dan Hunt, 1994).

Hubungan antara kualitas pelayanan dengan komitmen pelanggan didasarkan pada konsep loyalitas pelanggan yang dapat dibangun melalui 4 tahap, yaitu loyalitas kognitif, 
loyalitas afektif, loyalitas konatif dan loyalitas tindakan. Dalam tahapan tersebut kualitas pelayanan dimasukkan sebagai loyalitas kognitif, kepuasan pelanggan dimasukkan sebagai loyalitas afektif, sedangkan komitmen pelanggan dimasukkan sebagai loyalitas konatif (Dharmmesta, 1999).

Komitmen pelanggan diyakini sebagai variabel sentral dalam relationship marketing (Morgan dan Hunt, 1994). Sedangkan Berry dan Parasuraman (1991) berpendapat bahwa relationship marketing dalam bisnis jasa dapat dibangun melalui pondasi mutual commitment, sedangkan mutual commitment dipengaruhi oleh kualitas pelayanan yang diterima pelanggan. Selain itu, komitmen pelanggan dapat dibangun melalui kualitas pelayanan superior yang diterima pelanggan dari organisasi apabila dibandingkan dengan kualitas pelayanan organisasi lainnya (Dick dan Basu, 1994).

Para ahli menyetujui bahwa komitmen merupakan faktor sentral dari relationship marketing (Morgan dan Hunt, 1994). Gilliland dan Bello (2002) mempertimbangkan kaitan antara komitmen, trust dan loyalitas dan secara empirik terbukti bahwa trust merupakan anteseden dari komitmen dan loyalitas. Korelasi yang tinggi antara trust dengan komitmen ditemukan oleh beberapa peneliti. Demikian pula dari hasil studi Moorman, Deshpande dan Zaltman (1992) yang menemukan bahwa trust secara signifikan berpengaruh terhadap komitmen hubungan. Hal ini mendukung hasil studi Lang (2013) yang menunjukkan trust pelanggan merupakan anteseden komitmen pelanggan.

Kesimpulan sementara yang akan dibuktikan kebenarannya dalam penelitian ini adalah sebagai berikut :

H1: Kualitas pelayanan mempunyai pengaruh yang signifikan terhadap komitmen pelanggan.

H2 : Trust pelanggan mempunyai pengaruh yang signifikan terhadap komitmen pelanggan.

H3 : Interaksi antara kualitas pelayanan dan trust pelanggan lebih menjelaskan variance komitmen pelanggan daripada masing-masing variabel..

\section{METODE}

Populasi merupakan jumlah keseluruhan dari unit analisa yang ciri-cirinya akan diduga. (Mantra dan Kastro, 1989). Populasi dalam penelitian ini adalah pelanggan pada Pamella Swalayan di kota Yogyakarta.

Sampel ditentukan dengan metode convenience sampling dan metode purposive sampling. Convenience sampling merupakan sampel non probabilitas yang tidak terbatas (Cooper dan Emory, 1995). Convenience sampling merupakan suatu metode untuk memilih anggota populasi yang paling mudah untuk ditemui dan dimintai informasi (Hadi, 1987). Sedangkan purposive sampling merupakan metode pemilihan sampel berdasarkan pertimbangan tertentu (Cooper dan Emory, 1995; Babbie, 1995). Adapun kriterianya sebagai berikut :

a. Pelanggan yang dijadikan sampel merupakan pelanggan yang sering berbelanja di Pamella Swalayan. Dari bermacam-macam kelompok masyarakat yang menjadi pelanggan, yang dipilih sebagai responden adalah kelompok mahasiswa. Kelompok pelanggan ini dipilih karena merupakan salah satu kelompok masyarakat yang sering berbelanja dalam rangka pemenuhan kebutuhan sehari-hari.

b. Responden merupakan pelanggan pada Pamella Swalayan di kota Yogyakarta. Pamella Swalayan dipilih karena merupakan swalayan yang dimiliki oleh pengusaha lokal di Yogyakarta.

Dalam penelitian ini populasinya tidak terbatas, sehingga jumlah sampel ditentukan sebesar 100 responden. Penentuan jumlah sampel didasarkan pada pendapat Rescoe 
dalam Sekaran (1992) yang menyatakan bahwa jumlah sampel lebih besar dari 30 dan kurang dari 500, pada sebagian besar penelitian sudah mewakili.

Data yang digunakan dalam penelitian ini terdiri dari data primer dan data sekunder. Data primer digunakan sebagai bahan untuk menghitung variabel-variabel penelitian. Pengumpulan data primer dilakukan dengan cara memberikan daftar pertanyaan kepada responden yang berisi tentang kualitas pelayanan, trust pelanggan dan komitmen pelanggan. Sedangkan data sekunder dikumpulkan melalui studi kepustakaan yang digali dari buku, jurnal ilmiah, serta publikasi hasil-hasil penelitian. Data sekunder ini digunakan untuk menyusun rumusan masalah, hipotesis, tinjauan pustaka, serta penggunaan alat analisis.

Variabel penelitian diukur dengan menggunakan instrumen dalam bentuk kuesioner, yang berisi sejumlah pertanyaan secara tertulis guna memperoleh data dari responden. Instrumen tentang kualitas pelayanan digunakan dari instrumen yang disusun oleh Dabholkar, Thorpe dan Rentz (1996) yang mengajukan lima dimensi kualitas jasa pada bisnis ritel, yaitu : (1) Physical Aspects, (2) Reliability, (3) Personal Interaction, (4) Problem Solving, (5) Policy. Kelima dimensi ini terdiri dari 28 item, dan masing-masing diukur dengan menggunakan skala likert 7 point.

Trust pelanggan diukur dengan menggunakan instrument yang dikembangkan berdasar pada Garbarino dan Johnson (1999). Trust pelanggan terdiri dari 7 item yang diukur dengan menggunakan skala 7 point.

Komitmen pelanggan diukur dengan menggunakan instrument yang dikembangkan berdasar pada Gundlach et.al (1995), Garbarino dan Johnson (1990). Komitmen pelanggan diukur dengan menggunakan dua dimensi yaitu komitmen afektif dan komitmen continue. Kedua dimensi ini terdiri dari 18 item yang diukur dengan menggunakan skala 7 point.

Untuk mendapatkan data yang berkualitas, maka instrumen penelitian harus diuji validitas dan reliabilitasnya (Huck dan Cormier, 1996). Uji validitas dilakukan untuk mengukur apa yang ingin diukur (Ancok, 1989). Untuk menguji validitas instrumen penelitian ini digunakan Pearson Product Moment Test. Sedangkan uji reliabilitas dilakukan untuk mengetahui sejauhmana hasil suatu pengukuran dapat dipercaya (Azwar, 1997). Untuk menguji reliabilitas instrumen penelitian ini digunakan Cronbach Alpha.

Untuk melakukan pembuktian hipotesis, penelitian ini menggunakan metode analisis statistik. Analisis statistik digunakan untuk membuktikan adanya hubungan antara kualitas pelayanan, trust pelanggan dan komitmen pelanggan. Model dalam penelitian ini menggunakan model yang dikemukakan oleh Taylor dan Baker (1994), yaitu Moderator Regression Analysis (MRA). Adapun model yang digunakan dalam penelitian ini dapat dirumuskan sebagai berikut :

$Y=\alpha+\beta_{1} X+\beta_{2} Z+\beta_{3} X Z$

Dimana :

$\mathrm{Y}=$ Variabel dependen (komitmen pelanggan)

$\alpha \quad=$ Konstanta

$\beta_{1}, \beta_{2}, \beta_{3}=$ Koefisien Regresi

$\mathrm{X} \quad=$ Variabel independen (kualitas pelayanan)

$\mathrm{Z}=$ Variabel moderator (trust pelanggan)

$\mathrm{XZ} \quad=$ Interaksi antara kualitas pelayanan dengan trust pelanggan

Untuk menguji hipotesis yang dikemukakan, maka digunakan uji t dan uji F. Uji t dimaksudkan untuk mengetahui variabel bebas (independen variabel) yang berpengaruh secara signifikan terhadap variabel terikat secara individual. Sedangkan uji F digunakan untuk mengetahui apakah secara bersama-sama variabel-variabel bebas tersebut dapat menjelaskan variabel terikat. 


\section{ANALISIS DAN PEMBAHASAN}

Hasil uji validitas instrumen dengan menggunakan Pearson Product Moment Test menunjukkan bahwa item-item dari variabel kualitas pelayanan, trust pelanggan dan komitmenpelangganmenghasilkan $\mathrm{R}$ hitung lebih besar dari $\mathrm{R}$ tabel dengan probabilitas < 0,05 . Hasil ini menunjukkan bahwa semua item yang digunakan dalam penelitian ini dinyatakan valid. Sedangkan hasil uji reliabilitas dengan menggunakan cronbach Alpha menunjukkan bahwa variabel kualtias pelayanan, trust pelanggan dan komitmen pelanggan menghasilkan nilai Alpha lebih besar dari 0,50. Hal ini menunjukkan bahwa variabel kualitas pelayanan, trust pelanggan dan komitmen pelanggan dinyatakan reliabel (andal).

Hasil uji pengaruh Kualitas Pelayanan, Trust Pelanggan dan interaksi antara Kualitas Pelayanan dengan Trust Pelanggan terhadap Komitmen Pelanggan.

Moderator Regression Analysis (MRA) dari Taylor dan Beker (1994) digunaan untuk menganalisis pengaruh kualitas pelayanan, trust pelanggan dan interaksi antara kualitas pelayanan dengan trust pelanggan terhadap komitmen pelanggan. MRA dapat dianalisis melalui tiga persamaan regresi dengan membandingkan nilai $\mathrm{R}^{2}$ dari masing-masing persamaan untuk menentukan tipe efek moderator yang terjadi. Persamaan pertama, memasukkan variabel kualitas pelayanan sebagai variabel bebas. Persamaan kedua memasukkan variabel kualitas pelayanan dan trust pelanggan sebagai variabel bebas. Sedangkan persamaan ketiga memasukkan variabel kualitas pelayanan, trust pelanggan serta interaksi antara kualitas pelayanan dengan trust pelanggan sebagai variabel bebas.

MRA yang digunakan dalam penelitian ini, dapat dirumuskan sebagai berikut : $\mathrm{Y}=\alpha+\beta_{1} \mathrm{X}+\beta_{2} \mathrm{Z}+\beta_{3} \mathrm{XZ}$

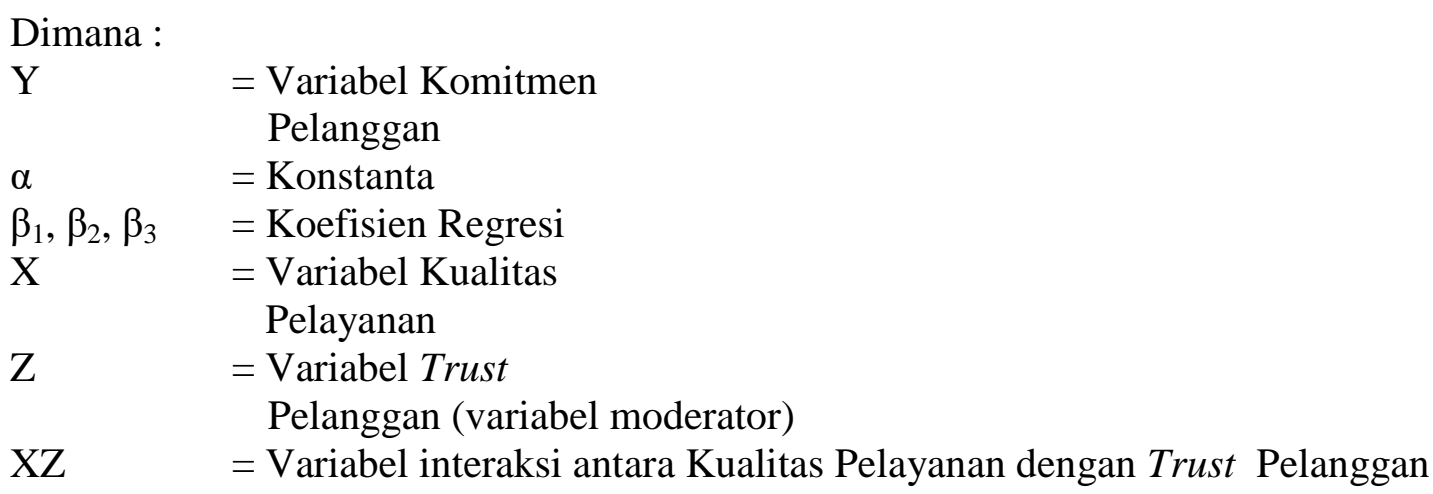

Hasil analisis regresi dari 100 responden pelanggan Pamella Swalayan dapat disajikan melalui tabel sebagai berikut :

Tabel 1. Hasil Analisis Regresi

\begin{tabular}{llcccccc}
\hline Model & \multicolumn{1}{c}{ Variabel } & $\boldsymbol{\alpha}$ & $\boldsymbol{\beta}$ & Nilai t & Prob. & $\mathbf{R}^{2}$ & Nilai F \\
\hline 1 & Kualitas Pelayanan (X) & 0,946 & 0,812 & 15,343 & 0,000 & 0,706 & 235,397 \\
2 & Kualitas Pelayanan (X) & 0,352 & 0,371 & 5,020 & 0,000 & 0,811 & 207,785 \\
& Trust Pelanggan (Z) & & 0,566 & 7,326 & 0,000 & & \\
3 & Kualitas Pelayanan (X) & 0,818 & 0,215 & 2,054 & 0,043 & 0,819 & 144,671 \\
& Trust Pelanggan (Z) & & 0,443 & 4,601 & 0,000 & & \\
& Interaksi (XZ) & & 0,038 & 2,074 & 0,041 & & \\
\hline
\end{tabular}

Sumber : Data Primer, diolah 
Atas dasar tabel 1 tersebut diatas, maka dapat dijelaskan sebagai berikut :

1. Model 1 (Persamaan Pertama)

Model persamaan pertama dapat dirumuskan sebagai berikut :

$\mathrm{Y}=0,946+0,812 \mathrm{X}$

Model persamaan pertama menunjukkan besarnya konstanta (intersep) sebesar 0,946. Variabel komitmen pelanggan akan mengalami keunikan sebesar 0,946 apabila variabel kualitas pelayanan sama dengan nol dengan koefisien regresi $\left(\beta_{1}\right)$ sebesar 0,812 .

Hasil uji t dengan $\alpha=5 \%$ menunjukkan bahwa kualitas pelayanan berpengaruh signifikan terhadap komitmen pelanggan dengan nilai $\mathrm{t}$ hitung sebesar 15,343 dan probabilitas sebesar $0,000<0,05$. Sedangkan hasil uji $\mathrm{F}$ dengan $\alpha=5 \%$ menunjukkan nilai $F$ sebesar 235,397 dengan probabilitas $0,000<0,05$. Hal ini berarti kualitas pelayanan berpengaruh signifikan terhadap komitmen pelanggan. Nilai $\mathrm{R}^{2}$ sebesar 0,706 menunjukkan bahwa 70,6\% variance komitmen pelanggan ditentukan oleh variance kualitas pelayanan . dengan demikian kualitas pelayanan dapta menjelaskan komitmen pelanggan sebesar $70,6 \%$. Sedangkan sisanya sebesar $29,4 \%$ disebabkan oleh variabel lain yang tidak dimasukkan dalam model penelitian.

2. Model 2 (Persamaan Kedua)

Model persamaan kedua dapat dirumuskan sebagai berikut :

$\mathrm{Y}=0,352+0,371 \mathrm{X}+0,566 \mathrm{Z}$

Model persamaan kedua menunjukkan nilai konstanta (intersep) sebesar 0,352. Hal ini berarti bahwa rata-rata komitmen pelanggan akan mengalami kenaikan sebesar 0,352 apabila variabel kualitas pelayanan dan trust pelanggan sama dengan nol. Koefisien regresi kualitas pelayanan $\left(\beta_{1}\right)$ sebesar 0,371 menunjukkan bahwa apabila terjadi variabel kualitas pelayanan 1 ceteris paribus akan meningkatkan variabel komitmen pelanggan sebesar 0,371 . Koefisien regresi trust pelanggan $\left(\beta_{2}\right)$ sebesar 0,566 menunjukkan bahwa apabila terjadi kenaikan variabel trust pelanggan 1 ceteris paribus akan meningkatkan variabel komitmen pelanggan sebesar 0,566.

Hasil uji t dengan $\alpha=5 \%$ menunjukkan thitung sebesar 5,020 dengan probabilitas sebesar $0,000<0,05$. Hal ini berarti variabel kualitas pelayanan secara parsial berpengaruh signifikan terhadap komitmen pelanggan. Hasil uji t pengaruh variabel trust pelanggan terhadap komitmen pelanggan dengan nilai t sebesar 7,326 dengan probabilitas $0,000<0,05$. Hal ini berarti variabel trust pelanggan berpengaruh signifikan terhadap komitmen pelanggan.

Hasil uji F menunjukkan F hitung sebesar 207,785 menunjukkan bahwa variabel bersama-sama berpengaruh terhadap komitmen pelanggan.

Nilai $\mathrm{R}^{2}$ sebesar 0,811 menunjukkan bahwa variance komitmen pelanggan ditentukan oleh variance kualtias pelayanan dan trust pelanggna. Hal ini berarti variabel kualitas pelayanan dan trust pelangan secara bersama-sama mampu menjelaskan komitmen pelanggan sebesar $81,1 \%$. Sedangkan sisanya yang sebesar $18,9 \%$ disebabkan oleh variabel lain yang tidak dimasukkan dalam model penelitian.

\section{Model 3 (Persamaan Ketiga)}

Model persamaan ketiga memasukkan kualitas pelayanan, trust pelanggan serta interaksi antara kualitas pelayanan dengan trust pelanggan sebagai variabel bebas. model persamaan ketiga dapat dirumuskan sebagai berikut:

$\mathrm{Y}=0,818+0,215 \mathrm{X}+0,443 \mathrm{Z}+0,038 \mathrm{XZ}$

Konstanta persamaan ketiga sebesar 0,818 menunjukkan variabel komitmen pelanggan akan mengalami kenaikan sebesar 0,818 apabila variabel kualitas pelayanan, 
trust pelanggan, serta interaksi antara kualitas pelayanan dengan trust pelanggan sama dengan nol.

Koefisien regresi kualitas pelayanan sebesar 0,215 menunjukkan apabila terjadi kenaikan kualitas pelayanan sebesar 1 ceteris paribus akan meningkatkan komitmen pelanggan sebesar 0,215. Koefisien regresi trust pelanggan sebesar 0,443 menunjukkan apabila terjadi kenaikan trust pelanggan sebesar 1 ceteris paribus akan meningkatkan komitmen pelanggan sebesar 0,443. Koefisien regresi interaksi antara kualitas pelayanan dengan trust pelanggan sebesar 0,038 1 ceteris paribus akan meningkatkan komitmen pelanggan sebesar 0,038 .

Hasil uji t dengan $\alpha=5 \%$ menunjukkan bahwa pengaruh kualitas pelayanan dengan nilai t sebesar 2,054, pengaruh trust pelanggan dengan nilai t sebesar 4,601, serta pengaruh interaksi antara kualitas pelayanan dengan trust pelanggan dengan nilai t sebesr 2,074. Hasil ini menunjukkan bahwa secara parsial variabel kualitas pelayanan, trust pelanggan, serta interaksi antara kualitas pelayanan dengan trust pelanggan berpengaruh secara signifikan terhadap variabel komitmen pelanggan. Hasil uji $\mathrm{F}$ menunjukkan $\mathrm{F}$ hitung sebesar 144,671. Hal ini berarti variabel kualitas pelayanan, trust pelanggan serta interaksi antara kualitas pelayanan dengan trust pelanggan secara bersama-sama berpengaruh terhadap komitmen pelanggan.

Nilai $\mathrm{R}^{2}$ sebesar 0,819 menunjukkan bahwa variance komitmen pelanggan ditentukan oleh variance kualitas pelayanan, trust pelanggan serta interaksi antara kualitas pelayanan dengan trust pelanggan sebesar 81,9\%. Hal ini berarti kualitas pelayanan, trust pelanggan serta interaksi antara kualitas pelayanan dengan trust pelanggan mampu menjelaskan variabel komitmen pelanggan sebesar $81,9 \%$. Sedangkan sisanya sebesar $18,1 \%$ disebabkan oleh variabel lain yang tidak dimasukkan dalam model penelitian.

\section{Pembahasan}

Berdasarkan hasil analisis data menunjukkan bahwa trust pelanggan sebagai variabel moderator mempunyai efek yang signifikan terhadap pengaruh kualitas pelayanan dengan komitmen pelanggan. Hasil analisis data menunjukkan bahwa nilai $\mathrm{R}^{2}$ yang dihasilkan dari ketiga model persamaan mengalami peningkatan. Hal ini dapat ditunjukkan dari nilai $\mathrm{R}^{2}$ pada persamaan pertama sebesar $0,706, \mathrm{R}^{2}$ pada persamaan kedua sebesar 0,811 dan $\mathrm{R}^{2}$ pada persamaan ketiga sebesar 0,819 . Dengan demikian dapat dijelaskan bahwa nilai $\mathrm{R}^{2}$ pada persamaan yang ketiga lebih tinggi dari pada nilai $\mathrm{R}^{2}$ pada persaman kedua. Demikian pula nilai $\mathrm{R}^{2}$ pada persamaan kedua lebih tinggi dari nilai $\mathrm{R}^{2}$ pada persamaan yang pertama. Dengan demikian pada persamaan yang ketiga ketika memasukkan variabel kualitas pelayanan, trust pelanggan, srta interaksi antara kualitas pelayanan dengan trust pelanggan sebagai variabel bebas menghasilkan nilai $\mathrm{R}^{2}$ yang tertinggi dalam menjelaskan variance komitmen pelanggan. Hasil studi ini memperkuat model MRA yang ditemukan oleh Taylor dan Baker (1994).

\section{KESIMPULAN DAN SARAN}

\section{Kesimpulan :}

1. Hasil penelitian menunjukkan bahwa kualitas pelayanan mempunyai pengaruh yang signifikan terhadap komitmen pelanggan.

2. Hasil penelitian menunjukkan bahwa trust pelanggan mempunyai pengaruh yang signifikan terhadap komitmen pelanggan. 
3. Hasil penelitian menunjukkan bahwa interaksi antara kualitas pelayanan dan trust pelanggan lebih menjelaskan variance komitmen pelanggan daripada masing-masing variabel.

4. Hasil penelitian menunjukkan bahwa trust pelanggan sebagai variabel moderator mempunyai efek yang signifikan dari pengaruh kualitas pelayanan terhadap komitmen pelanggan.

5. Variabel kualitas pelayanan, trust pelanggan serta interaksi antara kualitas pelayanan dengan trust pelanggan mampu menjelaskan variabel komitmen pelanggan sebesar $81,9 \%$ dan sisanya sebesar $18,1 \%$ disebabkan varaibel lain yang tidak dimasukkan dalam model penelitian.

\section{Saran -saran}

1. Pamella Swalayan hendaknya senantiasa meningkatkan kualitas pelayanan, trust pelanggan dan komitmen pelanggan sehingga akan meningkatkan loyalitas pelanggan.

Pamella Swalayan hendaknya meningkatkan kepercayaan pelanggan melalui berbagai upaya untuk pemenuhan kebutuhan pelanggan dalam berbelanja serta pemberian pelayanan yang terbaik kepada pelanggan sehingga akan meningkatkan komitmen pelanggan berbelanja di Pamella

Swalayan.

\section{DAFTAR PUSTAKA}

Ancok, D. (1989), "Validitas dan Reliabilitas Instrumen Penelitian," M. Singarimbun dan S. Effendi (ed.), Metodologi Penelitian Survai, Yogyakarta : LP3ES.

Azwar, S. (1997), Reliabilitas dan Validitas, Yogyakarta : Pustaka Pelajar.

Babbie, E. (1995), The Practice of Social Research, 7 th ed. Belmont : Wadsworth Publishing Company.

Berry, L.L. dan A. Parasuraman (1991), Marketing Service: Competing Through Quality, New York: The Free Press.

Berry, L.L. (1995), "Relationship Marketing of Service - Growing Interest. Emerging Perspective," Journal of the Academy of Marketing Science, Vol. 23, No. 4, p. 236 245.

Bitner, M.J. (1990), "Evaluating Service Encounters : The Effecs of Physical Surrounding and Employee Responses," Journal of Marketing, No. 54, April p. 69 - 82.

Bitner, M.J. B.H. Booms, dan L.A. Mohr. (1994), "Critical Service Encounters: The Employeers Viewpoint,” Journal of Marketing, Vol. 58, October, p. 95 - 106. 
Dabholkar, P.A., D.I. Thorpe dan J.O. Rentz (1996), “A Measure of Service Quality For Retail Store : Scale Development and Validation." Journal of The Academy Marketing Science, Vol. 24, No. 1, p. 3 - 16.

Dharmmesta, B.S. (1999), "Loyalitas Pelanggan: Sebuah Kajian Konseptual Sebagai Panduan Bagi Peneliti," Jurnal Ekonomi dan Bisnis Indonesia, Vol. 14, No. 3, p. 73 88.

Dick, A.S. dan K. Basu (1994), "Customer Loyalty: Toward an Integrated Conceptual Framework," Journal of The Academy of Marketing Science, Vol. 22, No. 2 (Spring), p. $99-113$.

Dwyer, F.R., P.H. Schurr dan S. Oh's (1987), "Developing Buyer - Seller Relationship," Journal of Marketing, April, Vol. 51, p. 11 - 27.

Fitzsimmons, J.A. dan M.J. Fitzsimmons (1994), Service Management For Competitive Advantage, New York: Mc. Graw - Hill Inc.

Garbarino, E., dan M.S. Johnson (1999), "Different Roles of Satisfaction, Trust, and Commitment In Customer Relationship," Journal of Marketing, April, p. 70 - 86.

Gilliland, D.I, dan D.C. Bello (2002), "Two Sides to Attitudinal Commitment: The Effect of Calculative and Loyalty Commitment on Enforcement Mechanism In Distribution Channels," Journal of The Academy of Marketing Science, Vol. 30, No. 1, p.24-43

Gulati, R. (1995), "Does Familiarity Breed Trust? The Implications of Repeated Ties for Contractual Choices In Alliances," Academy of Management Journal, January, Vol. 38 , p. $85-112$.

Hadi, S. (1987), Metodologi Research, Jilid I, Yogyakarta : Yayasan Penerbit Fakultas Psikologi UGM.

Huck, S.W. dan W.H. Cormier (1996), Reading Statistics and Research, $2^{\text {nd }}$ ed,. New York : Harper Collins Publisher Inc.

Kotler, P. (1997), Marketing Management : Analysis, Planning, Implementation and Control, $9^{\text {th }}$ ed. Upper Saddle River. New Jersey; Prentice Hall Inc. 
Lau, G.T. dan S.H. Lee (1999), "Consumers Trust In Brand and The Link to Brand Loyalty," Journal of Market Focused Management, No. 4, p. 341 - 370.

Mantra, I.B. dan Kasto (1989), "Penentuan Sampel," M. Singarimbun dan S. Effendi (ed.), Metode Penelitian Survai, Yogyakarta : LP3ES

Moorman, C., G. Zaltman dan R. Desphande (1992), "Relationship Between Provider and User of Market Research: The Dynamic of Trust Within and Between Organization," Journal of Marketing Research, Vol. 29, p. 314 - 328.

Morgan, R.Mj. dan S.D. Hunt (1994), "The Commitment Trust Theory of Relationship Marketing," Journal of Marketing, Vol. 58, No. 3, p.20-23.

Parasuraman, A.,V.A. Zeithaml dan L.L. Berry (1985), “A Conceptual Model of Service Quality and Impliation of Future Research, "Journal of Marketing, Vol. 49, p. 41-55

(1988), "SERVQUAL : A Multiple - Item Scale For Measuring Consumer Perceptions of Service Quality," Journal of Retailing, Vol. 64, No. 1, p. 12-14.

Rowley, J. dan Jl. Dawes (1999), "Customer Loyalty - a Relevant Concept for Libraries," Library Management, Vol.20 (6), p. 345-351

Taylor, A.S. dan L.T. Baker (1994), “An Assessment of Realtionship Between Service Quality and Customer Satisfaction in The Formation of Consumers' Purchase Intention, "Journal of Retailing. Vol. 70, No. 2, p.163-178.

Zeithaml, V.A., L.L. Berry dan Parasuraman (1996), “The Behavioral Consequences of Service of Service Quality, "Journal of Marketing, Vol. 60, p. 31-46. 